Tarbawi: Jurnal Ilmu Pendidikan p-ISSN:1858-1080 | e-ISSN: 2615-6547

Vol. 16, No. 2, Desember 2020, 148 - 153

\title{
Efektivitas Video Tutorial Untuk Meningkatkan Keterampilan Vokasional Membuat Souvenir Bagi Anak Tunagrahita Ringan
}

\author{
Kena Gustika Sari, Irdamurni Irdamurni \\ Universitas Negeri Padang \\ E-mail: kenagustika249@gmail.com
}

\begin{abstract}
Abstrak. Penelitian ini dilatarbelakangi oleh permasalahan seorang anak tunagrahita ringan yang memiliki keterampilan membuat souvenir yang sangat rendah sehingga perlu adanya pengajaran untuk meningkatkan keterampilan anak tunagrahita ringan agar mahir dalam membuat souvenir sehingga ini bisa menjadi bekal untuk anak dimasa yang akan datang dan dapat berkompetensi dalam dunia kerja. Tujuan dari penelitian ini adalah untuk menguji efektivitas dari video tutorial dalam meningkatkan kemampuan membuat souvenir dari saputangan handuk di SLB Muhammadiyah nanggalo padang. Jenis penelitian yang digunakan yaitu single subjek research dengan design A-B-A. kondisi baseline A1 terdiri dari empat kali pertemuan, kondisi intervensi terdiri dari tujuh kali pertemuan dan kondisi baseline kedua (A2) terdiri dari tiga kali pertemuan. Metode yang digunakan dalam pengumpulan data pada penelitian ini menggunakan pencatatan kejadian dengan mengumpulkan data pada saat anak membuat souvenir dari saputangan handuk. Berdasarkan pengamatan langsung, data dianalisis mengguanakan analisis visual dan grafik. Hasil penelitian menyatakan bahwa video tutorial membuat souvenir dari saputangan handuk dapat meningkatkan kemampuan keterampilan vokasional pada saat proses pembelajaran dan bertujuan untuk kelangsungan hidup dimasa yang akan datang.
\end{abstract}

Kata kunci: Keterampilan Vokasional, Pembuatan Souvenir, Video Tutorial, Tunagrahita Ringan

\begin{abstract}
This research is motivated by the problem of a mild mentally retarded child who has very low skills to make souvenirs so that there is a need for teaching to improve the skills of mild mentally retarded children so that they are proficient in making souvenirs so that this can be a provision for children in the future and can be competent in the world of work. The purpose of this research is to prove video tutorials in improving the ability to make souvenirs from handkerchiefs at SLB Muhammadiyah Nanggalo Padang. The type of research used is single subjek research with the $A-B-A$ design. Baseline $A 1$ condition consists of four meetings, the intervention condition consists of seven meetings and the second baseline condition consists of three meetings. The method used in data collection in this study was recording events by collecting data when children made souvenirs from handkerchiefs. Based on direct observation, the data were analyzed using visual and graphic analysis. The results of the study stated that the video tutorial for making souveni from handkerchief towels can improve vocational skills during the learning process and aims for survival in the future.
\end{abstract}

Keywords: Vocational Skills, Making Souvenirs, Tutorial Videos, Mild Mental Retardation 


\section{PENDAHULUAN}

Keterampilan vokasional disebut juga dengan keterampilan hidup.Keterampilan vokasional merupakan suatu kecakapan dalam melakukan suatu kegiatan/pekerjaan yang nantinya bisa menghidupi terutama untuk dirinya sendiri (Iswari, 2008). Tujuan diberikannya pembelajaran keterampilan vokasional yaitu untuk mengembangkan kemampuan kreativitas individu atau kelompok agar memiliki berbagai keahlian dan kemampuan untuk menghasilkan sesuatu yang dapat digunakan sebagai modal hidup di masyarakat dan juga untuk mempersiapkan peserta didik agar lebih terampil sesuai dengan minat dan bakat, sehingga peserta didik dapat berkompetensi dalam dunia kerja (Sehana, Ambarita, \& Siagian, 2015).

Salah satu bentuk keterampilan vokasional yang dapat diberikan kepada anak tunagrahita ringan adalah keterampilan membuat souvenir dari saputangan handuk. Keterampilan membuat souvenir dari saputangan handuk merupakan suatu kemampuan atau kepandaian yang dimiliki seorang anak untuk lebih berkreasi dalam memilih bentuk apa yang di inginkan seperti eskrim, kue (cake), lolypop dan masi banyak yang lain sehingga menjadi suatu kerya yang berbentuk lebih menarik dan bisa digunakan bagi orang banyak dan memiliki harga jual.

Tunagrahita disebut juga dengan anak gangguan intelektual. Anak tunagrahita termasuk dalam kelompok dibawah normal atau lebih lamban daripada anak normal, baik dari perkembangan sosial maupun kecerdasannya. Selain mengalami keterbelakangan dalam menyesuaikan diri dengan lingkungan, mereka kurang cakap dalam memikirkan hal-hal yang abstrak, yang rumit dan berbelit-belit (Irdamurni, 2018). Anak tunagrahita membutuhkan suatu layanan yang sesuai untuk mengatasi setiap masalah yang dialaminya. Layanan tersebut berguna bagi anak tunagrahita untuk mengoptimalkan berbagai kemampuannya sehingga mereka mampu dalam bekerja, bersosialisasi dan berkomunikasi untuk menyesuaikan dirinya dengan lingkungan disekitar mereka. Anak tunagrahita memerlukan pengawasan, layanan, perawatan dan dukungan serta pembelajaran yang sesuai secara teus menerus (Amriliyanto, 2013).

Tunagrahita dibagi menjadi empat klasifikasi yaitu tunagrahita ringan, sedang, berat dan sangat berat. Pada anak tunagrahita ringan rentang IQ nya antara 51-70 mereka mampu didik dan mampu latih seperti membaca, menulis, berhitung, menjahit, memasak, berketerampilan bahkan berjualan. Tunagrahita ringan lebih mudah diajak berkomunikasi. Selain kondisi fisik mereka tidak begitu mencolok, mereka bisa berlindung dari bahaya apapun, karena itu tunagrahita ringan memerlukan pengawasan ekstra (Sumekar, 2009). Pada umumnya sosialisasi anak tunagrahita ringan terhambat namun mereka masih mampu untuk berkembang baik dari segi akademik, sosial, dan kemampuan bekerja yang sederhana, sehingga mereka masih mampu mandiri tanpa terus tergantung pada orang lain (Kurniati, Amsyaruddin, \& Fatmawati, 2013).

Berdasarkan studi pendahuluan beberapa kali observasi di SLB Muhammadiyah Nanggalo Padang. Peneliti menemukan seorang anak dengan inisial Y kelas X SMA, mengalami kesulitan dalam mata pelajaran keterampilan pada materi membuat souvenir dari saputangan handuk. Hal ini dibuktikan dari hasil asesmen yang peneliti lakukan. Berdasarkan hasil asesmen yang peneliti lakukan dimulai dari menanyakan nama alat dan bahan yang digunakan anak cukup tau, namun nama alat dan bahan yang digunakan tersebut masih membingungkan bagi anak. Ketika peneliti menanyakan proses pembuatan souvenir dari saputangan handuk, anak mengalami kesulitan dalam mengurutkan proses pembuatan souvenir dari saputangan handuk melalui metode pengajaran secara langsung sehingga peneliti tertarik untuk menggunakan media video tutorial pada pembelajaran keterampilan.

Menurut (Rikarno, 2018) penggunaan video tutorial akan lebih cocok untuk mengajarkan pembelajaran yang bersifat praktek dengan langkah-langkah yang serinci mungkin. Melalui video tutorial anak tunagrahita ringan akan lebih tertarik dalam belajar dan memahami langkah demi langkah membuat souvenir dari saputangan handuk. Video tutorial dipilih karena merupakan media yang bersifat visual dan dapat diputar berkali-kali. Media video tutorial ini dirasa lebih 
efektif karena akan menarik perhatian siswa sehingga pembelajaran jadi lebih menyenangkan dan anak tidak cepat merasa bosan. Penelitian ini bertujuan untuk menguji efektivitas media video tutorial dalam meningkatkan keterampilan membuat souvenir dari saputangan handuk bagi anak tunagrahita ringan di SLB Muhammadiyah Nanggalo Padang.

\section{METODOLOGI}

Metode yang digunakan pada penelitian ini oleh peneliti yaitu metode eksperimen dengan menggunakan pendekatan single subjek research (SSR) dengan design penelitian yang digunakan yaitu A-B-A. Pada kondisi awal anak atau baseline (A1) diukur dengan waktu tertentu pada tahap intervensi (B) atau diberikannya perlakuan memiliki waktu tertentu, kemudian pada tahap setelah diberikannya perlakuan atau baseline (A2) memiliki ukuran waktu tertentu (Sunanto, Takeuci, \& Nakata, 2005). Pada penelitian ini subjek penelitian adalah siswa tunagrahita ringan di kelas X di SLB Muhammadiyah Nanggalo Padang. Untuk mengumpulkan data peneliti menggunakan teknik observasi dan tes. Alat pengumpulan data menggunakan pencatatan dengan bentuk persentase dengan kriteria penilaian; bisa dengan bobot nilai satu, kemudian tidak bisa dengan bobot nilai nol (Sugiyono, 2017). Selanjutnya untuk mengetahui presentase kemampuan siswa digunakan rumus berkut.

$$
\text { Presentase kemampuan siswa }=\frac{\text { skor perolehan }}{\text { skor total }} \times 100 \%
$$

\section{TEMUAN}

Penelitian ini dilakukan sebanyak 14 kali pertemuan yang dimana pada baseline A1 sebelum diberikan intervensi dilakukan sebanyak 4 kali pertemuan, selanjutnya pada kondisi B yaitu pemberian intervensi yang dilakukan sebanyak 7 kali pertemuan dan A2 merupakan kondisi baseline setelah tidak lagi diberikan intervensi sebanyak 3 kali pertemuan. Perbandingan antara A1, B dan A2 tersaji pada Gambar 1.

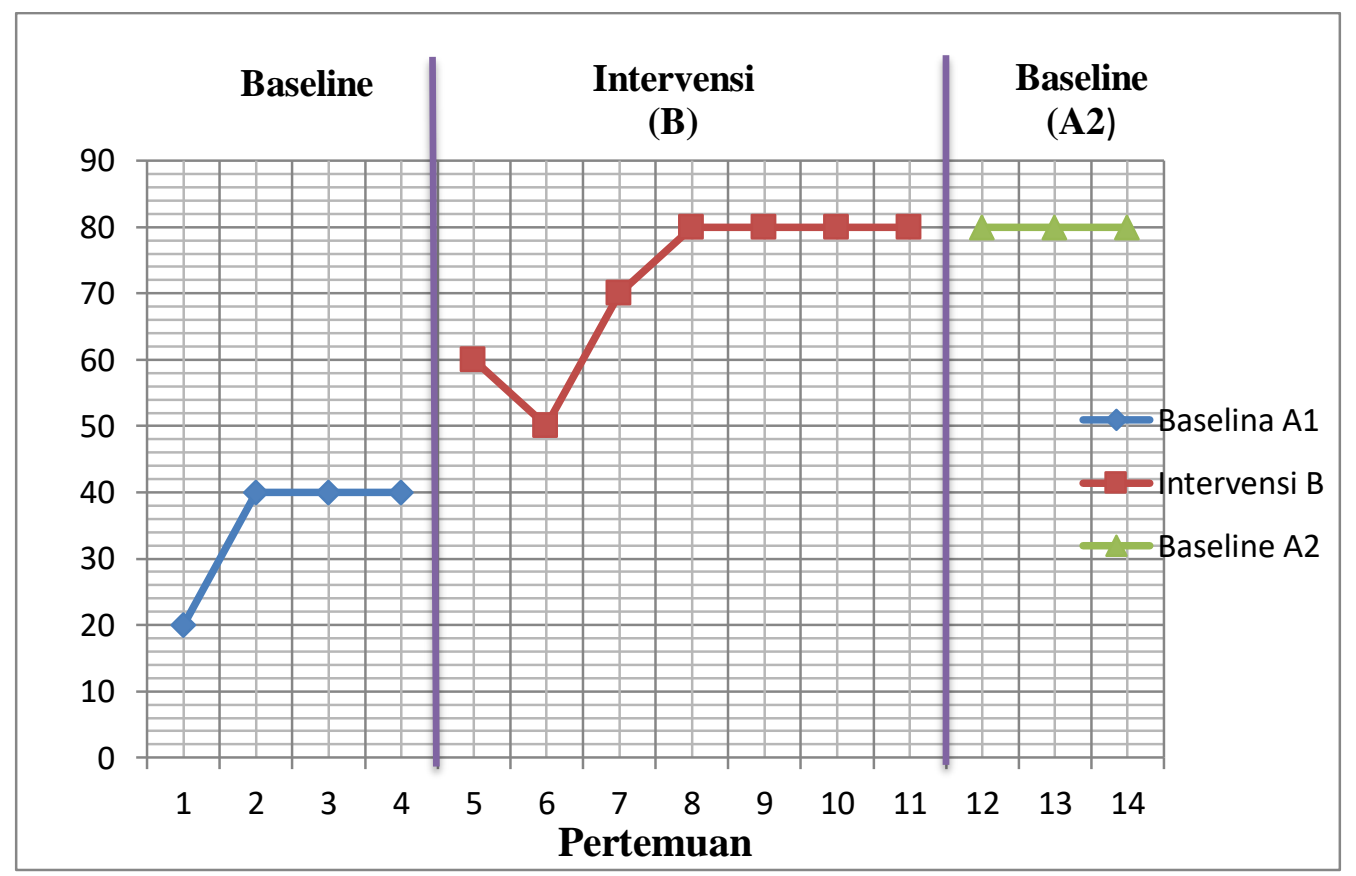

Gambar 1 Kondisi Data Keterampilan Membuat Souvenir Saputangan Handuk pada Anak Tunagrahita Ringan 
Berdasarkan Gambar 1, dapat dilihat bahawa pengamatan pada kondisi baseline (A1) dihentikan pada pertemuan keempat. Dari grafik tesebut dapat dilihat pada pertemuan pertama kemampuan keterampilan membuat souvenir dari saputangan handuk siswa adalah 2, pada pertemuan kedua, ketiga dan keempat kemampuan siswa menjadi 4, dan mean level pada kondisi baseline A1 adalah 3,5. Dengan demikian peneliti melanjutkan dengan memberikan intervensi pada kondisi Pada kondisi intervensi (B) yang dilakukan selama 7 kali pertemuan, intervensi dilakukan dengan memberikan video tutorial, pada pertemuan kelima kemampuan siswa adalah 6, pada pertemuan keenam kemampuan siswa adalah 5, pada pertemuan ketujuh kemampuan Siswa menjadi 7, kemudian pada pertemuan ke delapan sampai pertemuan kesebelas kmampuan Siswa adalah 8. Mean level pada kondisi intervensi adalah 7,14. Estimasi kecendrungan arah pada kondisi ini meningkat. Melihat pada kondisi pada saat anak diberikan intervensi sudah stabil maka peneliti melanjutkan pada kondisi baseline (A2) dengan tiga kali pertemuan dan mean levelnya adalah 8 dengan kecendrungan arah meningkat.

Tabel 1. Rangkuman Analisis Visual dalam Kondisi

\begin{tabular}{|c|c|c|c|c|c|}
\hline No & Kondisi & Target Behavior & $\mathbf{A}_{1}$ & B & $\mathbf{A}_{2}$ \\
\hline 1. & $\begin{array}{l}\text { Panjang } \\
\text { Kondisi }\end{array}$ & $\begin{array}{l}\text { Kemampuan } \\
\text { membuat souvenir } \\
\text { dari saputangan } \\
\text { handuk }\end{array}$ & 4 & 7 & 3 \\
\hline 2. & $\begin{array}{l}\text { Estimasi } \\
\text { kecendrungan } \\
\text { arah }\end{array}$ & $\begin{array}{l}\text { Kemampuan } \\
\text { membuat souvenir } \\
\text { dari saputangan } \\
\text { handuk }\end{array}$ & & & \\
\hline 3. & $\begin{array}{l}\text { Kecendrunga } \\
\text { n stabilitas }\end{array}$ & $\begin{array}{l}\text { Kemampuan } \\
\text { membuat souvenir } \\
\text { dari saputangan } \\
\text { handuk }\end{array}$ & $\begin{array}{c}0 \% \\
\text { (Tidak Stabil) }\end{array}$ & $\begin{array}{c}14,28 \% \\
\text { (Tidak Stabil) }\end{array}$ & $\begin{array}{l}100 \% \\
\text { (Stabil) }\end{array}$ \\
\hline 4. & Jejak data & $\begin{array}{l}\text { Kemampuan } \\
\text { membuat souvenir } \\
\text { dari saputangan } \\
\text { handuk }\end{array}$ & & & \\
\hline
\end{tabular}

Berdasarkan hasil rangkuman analisis visual di atas dapat disimpulkan bahwa kemampuan keterampilan vokasional membuat souvenir dari saputangan handuk menggunakan media video tutorial efektif.

\section{DISKUSI}

Penelitian ini meneliti tentang efektivitas video tutorial untuk meningkatkan keterampilan vokasional membuat souvenir bagi anak tunagrahita ringan di SLB Muhammadiyah Nanggalo Padang. Yang mana berdasarkan hasil pengamatan anak mengalami kesulitan dalam mengurutkan proses pembuatan souvenir dari saputangan handuk melalui metode pengajaran secara langsung sehingga peneliti tertarik untuk menggunakan media video tutorial pada pembelajaran keterampilan. Video tutorial merupakan rangkaian gambar yang ditanyangkan oleh seseorang yang berisi pesan pembelajaran yang membantu menunjang pemahaman terhadap materi 
pembelajaran yang digunakan sebagai bimbingan serta bahan pengajaran yang diberikan kepada peserta didik (Ghazi, Amsyaruddin, \& Irdamurni, 2018).

Penelitian ini memberikan intervensi menggunakan video tutorial. Dari hasil analisis data diketahui bahwa pengaruh intervensi menggunakan video tutorial dapat meningkatkan keterampilan membuat souvenir dari saputangan handuk anak tunagrahita ringan. Hal ini sama seperti penelitian DeVaney (2009) yang menyatakan bahwa video tutorial yang digunakan dalam penelitian tersebut dapat memberikan hasil yang baik, hal ini sama dengan kita bertatap muka dan video tutorial ini dinyatakan efektif salah satunya dalam bidang keterampilan vokasional, kaitannya yaitu penggunaan media video tutorial baik untuk diberikan dalam proses pembelajaran keterampilan vokasional.

Analisis data secara keseluruhan menunjukkan bahwa pengguanaan video tutorial dapat meningkatakan keterampilan membuat souvenir dari saputangan handuk bagi anak tunagrahita ringan dalam pembuatan souvenir towel cake atau disebut juga dengan kue saputangan handuk, karena media yang digunakan disesuaikan dengan karakteristik anak tunagrahita ringan. Sehingga anak tunagrahita ringan yang awalnya hanya bisa melakukan 2 dari 10 langkah pembuatan souvenir dari saputangan handuk, dengan adanya video tutorial yang diperlihatkan pada anak tunagrahita ringan sebagai sebuah panduan untuk membuat souvenir dari saputangan handuk, anak sudah bisa menyelesaikan setiap langkah-langkah pembuatan souvenir dari saputangan handuk dengan benar. Hal ini dapat dilihat dari hasil pembuatan souvenir dari saputangan handuk yang dibuat oleh anak tunagrahita ringan.

\section{SIMPULAN}

Berdasarkan hasil penelitian yang telah dilakukan di SLB Muhammadiyah Nanggalo Padang, dapat disimpulkan bahwa penggunaan media video tutorial ini dapat meningkatkan keterampilan membuat souvenir dari saputangan handuk bagi anak tunagrahita ringan. Dari hasil analisis data keseluruhan, analisis data dalam kondisi dan analisis data antar kondisi menunjukkan adanya peningkatan keterampilan membuat souvenir dari saputangan handuk bagi anak tunagrahita ringan melalui video tutorial. Perolehan hasil data ini menunjukkan bahwa video tutorial efektif dalam meningkatkan keterampilan membuat souvenir dari saputangan handuk anak tunagrahita ringan di SLB Muhammadiyah Nanggalo Padang. Berdasarkan penelitian ini peneliti memeberikan masukan kepada guru disekolah agar disediakannya media video tutorial untuk membantu pembelajaran yang bersifat praktek karena melalui video tutorial anak dapat melihat dan mempraktekkan langsung apa yang dipelajari dari video tutorial.

\section{REFERENSI}

Amriliyanto, A. (2013). Pembelajaran Chaning Bermedia Origami Terhadap Kemempuan Motorik Halus Anak Tunagrahita Sedang. Jurnal Pendidikan Khusus, 3(3).

DeVaney, T. A. (2009). Impact of video tutorials in an online educational statistics course. Journal of Online Learning and Teaching, 5(4), 600-608.

Ghazi, R. H., Amsyaruddin, A., \& Irdamurni, I. (2018). Video Tutorial Untuk Meningkatkan Keterampilan Memasang Kampas Rem Bagi Anak Tunagrahita Ringan. Jurnal Pendidikan Kebutuban Khusus, 2(1).

Irdamurni. 2018. Memahami Anak Berkebutuhan Khusus. Jawa Barat: Goresan Pena.

Iswari, M. 2008. Kecakapan Hidup Bagi Anak Berkebutuban Khusus. Padang: UNP Press.

Kurniati, Y., Amsyaruddin, A., \& Fatmawati, F. (2013). Efektifitas Tarian Untuk Meningkatkan Konsep Orientasi Ruang Bagi Anak Tunagrahita Ringan. Jurnal Penelitian Pendidikan Khusus, 2(2).

Rikarno, R. (2018). Pemanfaatan Handpone Android Sebagai Media Produksi Video Tutorial 
Pembelajaran Seni. Melayu Arts and Performance Journal, 1(1), 73-87.

Sehana, F., Ambarita, B., \& Siagian, S. (2015). Meningkatan Kemampuan Guru dalam Membelajarkan Keterampilan Vokasional kepada Anak Tunagrahita. Jurnal Pendidikan Dan Kepengawasan, 2(2), 41-52.

Sugiyono. 2017. Metode Penelitian Pendidikan Pendekatan Kuantitatif,Kualitatif, Dan R\&D. Bandung: Alfabeta.

Sumekar, G. (2009). Anak Berkebutuban Khusus Cara Membantu Mereka Agar Berbasil Dalam Pendidikan Inklusif. Padang: UNP Press.

Sunanto, J., Takeuchi, K., \& Nakata, H. (2005). Pengantar Penelitian Dengan Subjek Tunggal. Universitas Tsukuba: Crice. 